\title{
Efeito dos antibióticos gentamicina e cefalotina e do aminoácido taurina em meio de gema de ovo (Baken), sobre a longevidade e fertilidade do sêmen resfriado de eqüino
}

\section{Effect of the antibiotic gentamycin and cefalotyn and of the amino acid taurine on egg-yolk extender (Baken) on longevity and fertility of equine cooling semen}

\author{
Karen Mascaro Gonçalves da Silva, ${ }^{*}$ Frederico Ozanam Papa, ${ }^{*}$ Sandra Helena Gabaldi, ${ }^{\star}$ Adalberto José Crocci ${ }^{\star \star}$
}

\section{Resumo}

O presente experimento avaliou os efeitos dos antibióticos gentamicina e cefálotina e do aminoácido taurina no diluente Baken, sobre a longevidade e fertilidade do sêmen resfriado de eqüino. Para isso foram analisadas: motilidade progressiva, bacteriologia, teste hiposmótico e teste com sondas fluorescentes do sêmen nos momentos: sêmen fresco, pós-diluição, pós-resfriamento, 24 - 48 e 72 horas de armazenamento. Constatou-se que o diluente Baken contendo cefalotina e taurina foi o que apresentou melhor resposta de longevidade in vitro e que o mesmo foi parcialmente eficiente até 24 horas de resfriamento mediante os resultados de prenhez.

Palavras chave. eqüino, sêmen, resfriamento, integridade de membrana e fertilidade.

\begin{abstract}
This experiment tests the effect of the antibiotics gentamycin and cefalotyn and the amino acid taurine on extender Baken on longevity and fertility of equine cooled semen. The progressive motile, bacteriology, hypoosmotic test and fluorescent probe were mensured at moment: in natura semen, before extender, after extender, 24 - 48 and 72 hours of storage. The Baken extender with cefalotyn and taurine show the best results on longevity in vitro and was partly effective at 24 hours of cooling by means of fertility rate.
\end{abstract}

Keywords: equine, semen, cooling, membrane integrity and fertility.

\section{Introdução}

Sabe-se que os resultados de fertilidade obtidos com a utilização do resfriamento e transporte de sêmen são melhores do que aqueles observados quando da utilização do sêmen criopreservado (Klug, 1989).

Casos têm sido reportados nos quais bactérias patogênicas foram isoladas do sêmen de garanhões com taxa de concepção baixa, sem existir outro sinal de infecção (Hughes et al., 1967). Por isso, o sêmen eqüino tem que ser diluído em diluidores contendo antibióticos de amplo espectro (Kenney et al., 1975). Entretanto, os efeitos deletérios dos antibióticos sobre a célula espermática podem ser maiores no sêmen resfriado devido à sua exposição prolongada a estes ou a uma interação entre os efeitos detrimentais do resfriamento e da presença do antibiótico (Jasko et al., 1993).

Existem canais de proteínas por onde a água pode difundirse nas membranas celulares. Esses canais são moléculas proteicas que se estendem através da dupla camada lipídica comunicando as faces interna e externa da membrana (Swenson e Reece, 1996). Quando exposto a umá solução hiposmótica, o espermatozóide funcional irá apresentar. edema de cauda para restabelecer o equilíbrio osmótico, produzindo enrolamentos típicos de cauda (Zavos, 1990). Este é um processo de difusão do solvente através de uma membrana semipermeável a partir de uma solução de maior concentração do solvente para uma de menor concentração do solvente (Swenson e Reece, 1996).

\section{Material e métodos}

A avaliação in vitro do presente experimento foi desenvolvida nas dependências do Departamento de Reprodução Animal e Radiologia Veterinária da FMVZ-UNESP-Botucatu/SP e o teste in vivo realizado na Estação Experimental de Zootecnia em Colina e Fazenda Lageado - FMVZ - UNESP/Botucatu, SP.

Foram coletados 20 ejaculados de quatro garanhões. Após cada colheita, o sêmen foi imediatamente avaliado quanto à

\footnotetext{
* Faculdade de Medicina Veterinária e Zootecnia - UNESP - Departamento de Reprodução Animal e Radiologia Veterinária - Rubião Jr. s/n CEP 18618-000, Botucatu, SP: karen.mascaro@bol.com.br

**Faculdade de Medicina Veterinária e Zootecnia - UNESP Departamento de Bioestatística
} 
motilidade total, vigor, volume, concentração espermática. Cada ejaculado foi fracionado em duas amostras de igual volume, que sofreram diluição mínima de 1:3 de maneira a se alcançar uma concentração final de $25 \times 10^{6}$ espermatozóides $/ \mathrm{ml}$, com cada um dos seguintes diluidores com osmolaridade entre 353 e $360 \mathrm{mOsmol} / \mathrm{l}$ e $\mathrm{pH}$ entre 6,91 e 6,93:

- Baken (Nishikawa, 1959) mais $50 \mu \mathrm{g} / \mathrm{ml}$ de cefalotina e 6,25 $\mathrm{mg} / \mathrm{l}$ de taurina ${ }^{2}$ (BCT)

- Baken (Nishikawa, 1959) mais $50 \mu \mathrm{g} / \mathrm{ml}$ de gentamicina ${ }^{3}$ e $6,25 \mathrm{mg} / \mathrm{l}$ de taurina (BGT)

Concomitante a cada avaliação da motilidade, uma alíquota foi separada para verificar a bacteriologia do sêmen, a integridade da membrana plasmática utilizando-se a técnica descrita por Harrison e Vickers (1990) e modificada por Zúccari e Papa (1995) que emprega o diacetato de 6-carboxifluoresceína e o iodeto de propídio; e a avaliação da funcionalidade de membrana pelo teste hiposmótico com água destilada (Lomeo e Giambersio, 1991) modificada por Lagares et al. (1998) na diluição de 1:2 (sêmen: água destilada). O resfriamento das amostras a $37^{\circ} \mathrm{C}$ foi realizado em freezer, até atingir $5^{\circ} \mathrm{C}$, perfazendo uma curva de $0,5^{\circ} \mathrm{C} / \mathrm{min}$.

Mediante os resultados in vitro, onde o diluidor BCT apresentou superioridade sobre o BGT, optou-se por testa-lo in vivo. Para tal, foram utilizadas 50 éguas reprodutivamente sadias com idades variando entre três a dezoito anos e dois garanhões aptos à reprodução (três e seis anos de idade) divididas em três grupos: grupo 1: 10 éguas inseminadas, com sêmen do garanhão de seis anos de idade, na presença de um folículo $\geq 35 \mathrm{~mm}$, com dose única de $200 \times 10^{6}$ espermatozóides com motilidade progressiva, 36 horas após aplicação de 2500 UI de hCG intramuscular, com ovulação ocorrendo 24 horas após a inseminação com sêmen de 24 horas de refrigeração; grupo 2: 10 éguas inseminadas diariamente a partir de um folículo $\geq 35 \mathrm{~mm}$ e uma pós-ovulação, com sêmen do garanhão de seis anos de idade, refrigerado por 24 horas, e outras 10 éguas seguindo o mesmo protoco10, inseminadas com sêmen de 48 horas, na mesma dose do primeiro grupo; grupo 3: 10 éguas inseminadas diariamente e uma inseminação pós-ovulação com sêmen do garanhão de três anos de idade, refrigerado 24 horas, e outras 10 éguas seguindo o mesmo prctocolo, inseminadas com sêmen de 48 horas, ambas com doses de $500 \times 10^{6}$ espermatozóides com motilidade progressiva. Para o primeiro e segundo grupos de éguas, foi utilizada curva de resfriamento de $0,5^{\circ} \mathrm{C} / \mathrm{min}$. e no terceiro, curva de $0,05^{\circ} \mathrm{C} / \mathrm{min}$. O diagnóstico de gestação foi realizado por ultra-sonografia. Os animais com prenhez negativa foram inseminados no cio seguinte com sêmen diluido ao $\mathrm{BCT}$, sem refrigerar.

\section{Metodologia estatística}

O estudo comparativo entre diluidores em cada momento avaliado, para motilidade progressiva, teste hiposmótico e sondas fluorescentes foi feito pelo teste não-paramétrico de Wilcoxon (Zar, 1996). Já para a comparação entre momentos para cada tratamento foi litilizado o tesie de Freedman (Zar,

\footnotetext{
1 Cefalotina - Keflin - Ely Lilly

2 Taurine - produto T 0625 - Sigma

${ }^{3}$ Gentamicina - Shering do Brasil
}

1996). Para cada protocolo de inseminações utilizou-se o teste de Goodman (Goodman, 1989), comparando-se as proporções de prenhez observadas nos vários tratamentos caracterizados pelo número de horas de armazenamento. As diferenças foram consideradas significativas ao nível de probabilidade 0,05 .

\section{Resultados e discussão}

As colheitas utilizando-se o modelo clássico de vagina artificial geralmente contêm todos os jatos, incluindo a fração préejaculatória, assim como vários tipos de bactérias no sêmen do garanhão sem evidência de infecção, incluindo Pseudomonas aeruginosa, Klebsiella pneumoniae, Corinebacterium Equi, Aerobacter (Tischiner e Kosiniak, 1992). Klug e Scien (1992) investigaram o fluido préejaculatório no grupo de 176 garanhões no período da estação de monta e a incidència de tipos de bactérias potencialmente patogênicas foi: $4,9 \%$ Streptococcus b hemolitico, $4,3 \%$ de Klebsiella spp., 2,3\% Staphilococcus aureus, $2,3 \%$ de Pseudomonas aeruginosa e 1,1\% de Taylorella equigenitalis. Além do mais, existe uma alta ocorrência de isolamento de bactérias aeróbias potencialmente patogênicas no trato genital de garanhões (Kenney et al., 1983). Quando a colheita é com vagina artificial fechada, o sêmen entra em contato com o pênis, contaminando o ejaculado.

Redução do crescimento bacteriano foi observada nas amostras de sêmen preservadas a $5^{\circ} \mathrm{C}$ mas não a $20^{\circ} \mathrm{C}$ por 24 e 48 horas. Isto mostra que a eficácia do controle bacteriano é maior a $5^{\circ} \mathrm{C}$ (Vaillancourt et al., 1993). Neste trabalho foi encontrada uma grande variedade de bactérias, mas a maioria delas não mais estava presente após a adição dos antibióticos e refrigeração. A refrigeração aliada ao uso dos antibióticos pode ter contribuído para a redução de bactérias presentes no sêmen neste trabalho, principalmente nas 72 horas de refrigeração (Tabela 1).

No sêmen do garanhão, organismos gram-negativos e grampositivos podem ser po:encialmente patogênicos. Por isso, o uso de antibióticos de largo espectro ou a combinação de antibióticos onde se consiga um largo espectro nos extensores seminais deve ser utilizado (Squires et al., 1981; Blanchard et al., 1987). Uma variedade de drogas antibacterianas tem sido incorporada aos extensores seminais eqüino, porém, poucos estudos têm avaliado seus efeitos quanto ao controle de contaminantes bacterianos, particularmente as bactérias anaeróbias (Hoyumpa el al., 1992).

Dentre os antibióticos mais comumente utilizados podemos destacar: penicilina $G$ potássica, sulfato de gentamicina, sulfato de estreptomicina, amicacina, polimixina $B$, sulfato de kanamicina e ticarcilina dissódica (Jasko et al., 1993). Nenhum trabalho foi realizado até o momento utilizando-se as cefalotinas em meio extensor. Ele foi capaz de eliminar algumas espécies presentes no sêmen, mas não eliminá-las totalmente (Tabela 1). Este antibiótico é representativo da atividade antibacteriana do grupo das cefalosporinas e, para efeitos práticos, a sensibilidade dos germes a ela, determinada por teste in vitro, corresponde à dos demais componentes do grupo, com pequenas diferenças de espectro em relação a alguns deles. Caracterizam-se por sua atividade bactericida sobre germes gram-positivos e gram-negativos, provocando lise osmótica das células sensíveis em crescimento (Tavares, 1998). 
A gentamicina é um antibiótico extraído de culturas de fungos do gênero Micronospora e caracteriza-se por sua atividade sobre a Pseudomonas aeruginosa e Acinetobacter. Apresenta sinergismo de ação com as penicilinas, cefalosporinas e polimixinas (Tavares, 1998).

Varner et al. (1998) relataram que a gentamicina na concentração de 50 ou $500 \mu \mathrm{g} / \mathrm{mL}$ foi efetiva na redução do crescimento bacteriano no diluidor seminal, porém nenhuma concentração conseguiu eliminar todo o crescimento bacteriano, e nenhum antibiótico estudado fci capaz de eliminar organismos da família das enterobacteriáceas. Resposta parecida foi encontrada neste trabalho, onde a eficácia da gentamicina foi maior em relação a cefalotina, mesmo em concentrações baixas (Tabela 1).

Tabela 1: Resultado bacteriológico do sêmen resfriado in natura e diluído com extensores BCT e BGT e armazenado até 72 horas

\begin{tabular}{|c|c|c|}
\hline Extensor & $24 \mathrm{~h}$ de armazenamento & $72 \mathrm{~h}$ de armazenamento \\
\hline BCT & $\begin{array}{l}\text { Alcaligens faecalis } \\
\text { Staphylococcus spp } \\
\text { Enterobacter cloacal } \\
\text { Staphylococcus spp } \\
\text { Escherichia coli }\end{array}$ & $\begin{array}{l}\text { Corynebacterium spp } \\
\text { Alcaligens faecalis } \\
\text { Enterobacter cloacal }\end{array}$ \\
\hline BGT & $\begin{array}{l}\text { A/caligens faecalis } \\
\text { Staphylococcus spp }\end{array}$ & $\begin{array}{l}\text { Alcaligens faecalis } \\
\text { Citrobacter freundii }\end{array}$ \\
\hline Sêmen in natura & $\begin{array}{l}\text { Corynebacterium spp } \\
\text { Staphylococcus'spp } \\
\text { Streptococcus } \beta \text { hemoliticus } \\
\text { Pseudomonas aeroginosa } \\
\text { Micrococcus spp } \\
\text { Escherichia coli } \\
\text { Streptococcus sp? } \\
\text { Streptococcus a hiemoliticus }\end{array}$ & $\begin{array}{l}\text { Staphylococcus spp } \\
\text { Micrococcus spp } \\
\text { Corynebacterium spp } \\
\text { Citrobacter freundii } \\
\text { Pseudomonas spp } \\
\text { Escherichia coli } \\
\text { Bacillus spp } \\
\text { Streptococcus } \alpha \text { hemoliticus } \\
\text { Pseudomonas aeroginosa } \\
\text { Streptococcus } \beta \text { hemoliticus } \\
\text { Klebsiella pneumoniae }\end{array}$ \\
\hline
\end{tabular}

Tabela 2: Porcentagem de espermatozóides com motilidade progressiva, segundo diluente e momentos do sômen armazenado até 72 horas

\begin{tabular}{cccccc}
\hline \hline & & & & Momento & \\
\cline { 2 - 6 } Extensor & $\begin{array}{c}\text { Pós- } \\
\text { diluição }\end{array}$ & $\begin{array}{c}\text { Pós- } \\
\text { resfriamento }\end{array}$ & $\begin{array}{c}24 \mathrm{~h} \text { de arma- } \\
\text { zenamento }\end{array}$ & $\begin{array}{c}48 \mathrm{~h} \text { de arma- } \\
\text { zenamento }\end{array}$ & $\begin{array}{c}72 \mathrm{~h} \text { de arma- } \\
\text { zenamento }\end{array}$ \\
\hline \hline BCT & $40,0^{\mathrm{A}} \mathrm{b}$ & $40,0^{\mathrm{A}}$ & $45,0^{\mathrm{A}} \mathrm{a}$ & $40,0^{\mathrm{A}} \mathrm{b}$ & $30,0^{\mathrm{A}}$ \\
BGT & $42,5^{\mathrm{A}} \mathrm{a}$ & $42,5^{\mathrm{A}}$ & $40,0^{\mathrm{B}} \mathrm{b}$ & $32,5^{\mathrm{B}}$ & $20,0^{\mathrm{B}} \mathrm{b}$ \\
\hline \hline
\end{tabular}

*As letras maiúsculas comparam tratamentos para cada momento (colunas).

**As letras minúsculas comparaín momentos para cada tratamento (linhas).

> Letras iguais comparando-se tratamentos em cada momento não diferem estatisticamente pelo teste de Wilcoxon a $5 \%$ de probabilidade.

$>$ Letras iguais comparando-se moinentos para cada tratamento não diferem estatisticamente pelo teste de Freedinan a $5 \%$ de probabilidade.

BCT - Baken (NISHIKAWA, 1959) mais $50 \mu \mathrm{g} / \mathrm{mL}$ de cefalotina e $6,25 \mathrm{mg} / \mathrm{l}$ de taurina

BGT - Baken (NISHIKAWA, 1959) mais $50 \mu \mathrm{g} / \mathrm{mL}$ de gentamicina e $6,25 \mathrm{mg} / \mathrm{l}$ de taurina após a diluição, 48 e 72 horas de refrigeração, com superioridade do BCT, contendo cefalotina; sobre o BGT, contendo gentamicina. Apesar dos resultados superiores, a cefalotina foi prejudicial à membrana plasmática dos espermatozóides logo após o resfriamento e a gentamicina apenas a partir das 24 horas de armazenamento (Tabela 3).

Com os resultados observamos que houve diferença estatística entre os diluentes, na avaliação de integridade de membrana após 48 horas de armazenamento, com superioridade do BCT. A queda deste parâmetro no BGT ocorreu após o resfriamento, e no BCT, a partir de 24 horas (Tabela 4).

Os diluentes influenciaram de maneira diferente a funcionalidade e a integridade da membrana plasmática do espermatozóide após o resfriamento, onde houve queda dos valores de BGT com 24 horas de armazenamento em resposta ao ieste hiposmótico, e queda após o resfriamento quando avaliado com o uso de sondas fluorescentes. Resposta contrária ocorreu no BCT (Tabelas 3 e 4).

A correlação entre os testes de funcionalidade $e$ integridade de membrana foi positiva concordando com o que foi citado por Neild et al. (1999). Apesar da correlação positiva, os resultados apresentam-se dispersos na figura ao invés de seguirem todos em uma mesma reta. Esta resposta é devido ao baixo coeficiente de correlação $\left(r^{2}\right)$ do $B C T=0,2663(p=$ $0,0170) e^{2} r^{2}$ do $B G T=0,30298(p=$ 0,00630 ) (Figuras 1 e 2 respectivamente). Cada teste utilizado neste experimento avaliou aspectos diferentes da membrana mediante os resultados das Tabelas 3 e 4 e o teste de correlação, concordando com Lagares et al. (2000).

Geralmente, tenta-se inseminar éguas - mais próximo da ovulação possível, quando se utiliza sêmen resfriado. 0 manejo rormalmente utilizado é esperar até o sêmen transportado chegar à 
Tabela 3: Porcentagem de funcionalidade de membrana com o uso do teste hiposmótico, segundo extensor e momentos do sêmen armazenado até 72 horas.

\begin{tabular}{cccccc}
\hline \multirow{2}{*}{ Extensor } & \multicolumn{5}{c}{ Momento } \\
\cline { 2 - 6 } & $\begin{array}{c}\text { Pós- } \\
\text { diluição }\end{array}$ & $\begin{array}{c}\text { Pós- } \\
\text { resfriamento }\end{array}$ & $\begin{array}{c}24 \mathrm{~h} \text { de arma- } \\
\text { zenamento }\end{array}$ & $\begin{array}{c}48 \mathrm{~h} \text { de arma- } \\
\text { zenamento }\end{array}$ & $\begin{array}{c}72 \mathrm{~h} \text { de arma- } \\
\text { zenamento }\end{array}$ \\
\hline BCT & $63,0^{\mathrm{A}}{ }_{\mathrm{a}}$ & $59,5^{\mathrm{A}} \mathrm{b}$ & $55,5^{\mathrm{A}} \mathrm{b}_{\mathrm{b}}$ & $51,0^{\mathrm{A}}{ }_{\mathrm{c}}$ & $43,0^{\mathrm{A}}{ }_{\mathrm{d}}$ \\
BGT & $60,5^{\mathrm{B}} \mathrm{b}$ & $62,0^{\mathrm{A}}{ }_{\mathrm{a}}$ & $55,0^{\mathrm{A}} \mathrm{b}$ & $50,0^{\mathrm{B}}{ }_{\mathrm{c}}$ & $42,5^{\mathrm{B}}{ }_{\mathrm{d}}$ \\
\hline \hline
\end{tabular}

*As letras maiúsculas comparam tratamentos para cada momento (colunas).

*As letras minúsculas comparam momentos para cada tratamento (linhas).

$>$ Letras iguais comparando-se tratamentos em cada momento não diferem estatisticamente pelo teste de Wilcoxon a $5 \%$ de probabilidade.

$>$ Letras iguais comparando-se momentos para cada tratamento não diferem estatisticamente pelo teste de Freedman a $5 \%$ de probabilidade.

BCT - Baken (Nishikawa, 1959) mais $50 \mu \mathrm{g} / \mathrm{mL}$ de cefalotina e $6,25 \mathrm{mg} / \mathrm{l}$ de taurina

BGT - Baken (Nishikawa, 1959) mais $50 \mu \mathrm{g} / \mathrm{mL}$ de gentamicina e $6,25 \mathrm{mg} / \mathrm{l}$ de taurina

Tabela 4: Porcentagem de integridade de membrana com o uso do teste com sondas fluorescentes, segundo extensor e momentos do sêmen armazenado até 72 horas.

\begin{tabular}{cccccc}
\hline Extensor & $\begin{array}{c}\text { Pós- } \\
\text { diluição }\end{array}$ & $\begin{array}{c}\text { Pós } \\
\text { resfriamento }\end{array}$ & $\begin{array}{c}24 \mathrm{~h} \text { de arma- } \\
\text { zenamento }\end{array}$ & $\begin{array}{c}48 \mathrm{~h} \text { de arma- } \\
\text { zenamento }\end{array}$ & $\begin{array}{c}72 \mathrm{~h} \text { de arma- } \\
\text { zenamento }\end{array}$ \\
\hline BCT & $80,5^{\mathrm{A}}{ }_{\mathrm{a}}^{\mathrm{a}}$ & $81,5^{\mathrm{A}}$ & $62,0^{\mathrm{A}}{ }_{\mathrm{b}}$ & $55,0^{\mathrm{A}}{ }_{\mathrm{c}}$ & $40,5^{\mathrm{A}}{ }_{\mathrm{d}}$ \\
BGT & $80,0^{\mathrm{A}}{ }_{\mathrm{a}}$ & $79,5^{\mathrm{A}} \mathrm{b}$ & $60,5^{\mathrm{A}}$ & $52,0^{\mathrm{B}}{ }_{\mathrm{d}}$ & $40,0^{\mathrm{A}}$ \\
\hline
\end{tabular}

*As letras maiúsculas comparam tratamentos para cada momento (colunas).

**As letras minúsculas comparam momentos para cada tratamento (linhas).

$>$ Letras iguais comparando-se tratamentos em cada momento não diferem estatisticamente pelo teste de Wilcoxon a $5 \%$ de probabilidade.

> Letras iguais comparando-se momentos para cada tratamento não diferem estatisticamente pelo teste de Freedman a $5 \%$ de probabilidade.

BCT - Baken (Nishikawa, 1959) mais $50 \mu \mathrm{g} / \mathrm{ml}$. de cefalotina e $6,25 \mathrm{mg} / \mathrm{l}$ de taurina

BGT - Baken (Nishikawa, 1959) mais $50 \mu \mathrm{g} / \mathrm{mL}$ de gentamicina e $6,25 \mathrm{mg} / \mathrm{l}$ de taurina propriedade e depois utilizar hCG ou GnRH no momento da inseminação para que a égua ovule com 24 ou 48 horas após a aplicação do hormônio (Squires et al., 1998). Como não sabíamos os efeitos de fertilidade com o diluente utilizado, optamos em realizar as inseminações 36 horas após a aplicação do hCG, pois as éguas poderiam ovular com 12 horas após a inseminação, 48 horas após hCG, já que a rotina da propriedade não permitia controle folicular duas vezes ao dia.

Para o primeiro grupo de éguas onde se utilizou uma única dose inseminante de $200 \times 10^{6}$ espermatozóides viáveis 24 horas antes da ovulação, não foi observada prenhez com o sêmen de 24 horas de armazenamento (Tabela 5). Estes resultados foram inferiores àqueles encontrados na literatura (Squires et al., 1998; Lagares et al., 2000). Já no controle, onde foi utilizado sêmen diluído com extensor BCT e inseminado sem refrigeração, a taxa de prenhez foi de $100 \%$. Não se sabe ao certo o que acontece com a célula espermática, no trato reprodutivo da égua, depois que foi resfriado. Alguns autores sugerem que no resfriamento a $5^{\circ} \mathrm{C}$ a membrana acrossomal é mais permeável ao $\mathrm{Ca}^{++}$que a membrana mitocondrial. Isso faz com que haja vesiculação prematura dessa primeira membrana citada, explicando por que a fertilidade declina mais rapidamente que a motilidade (Elloy e Hall, 1987).

No grupo 2, onde as inseminações eram diárias, inclusive pós-ovulação, uma única prenhez foi detectada utilizando-se sêmen de 24 horas do armazenamento (Tabela 6). $O$ resultado não foi significativo $(p<0,05)$, diferindo do grupo inseminado com sêmen diluído e não resfriado, onde se obteve taxa de prenhez de $100 \%$. Resultados ainda in-

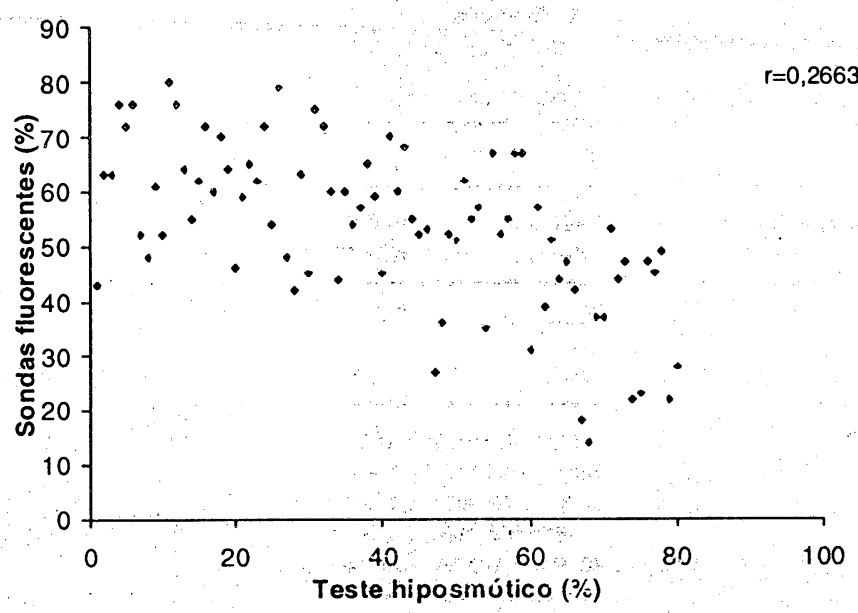

Figura 1: Representação gráfica da correlação entre o teste hiposmótico e o teste com sondas fluorescentes com o extensor BT2.

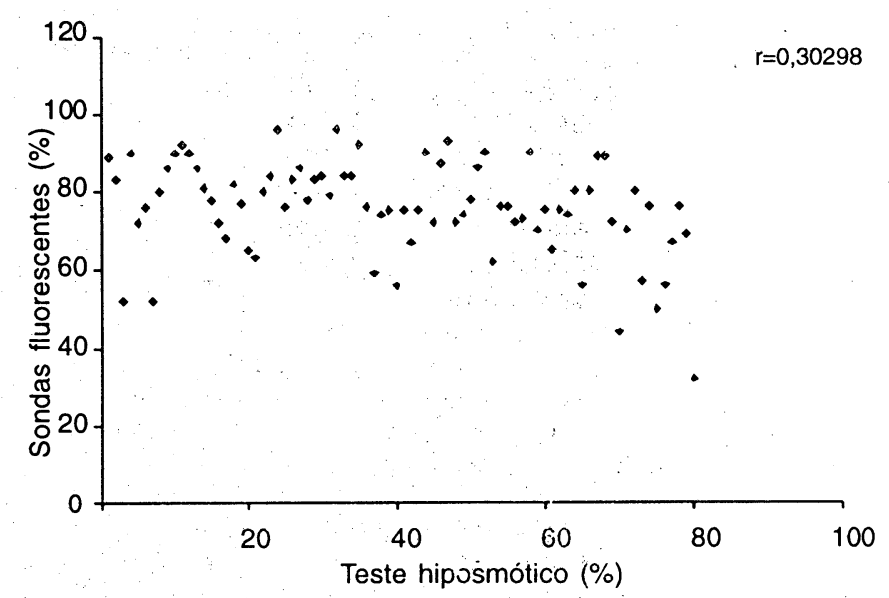

Figura 2: Representação gráfica da correlação entre o teste hiposmótico e o teste com sondas fluorescentes com o extensor BT3. 
Tabela 5: Resultado das inseminações com sêmen diluído em BCT, não resfriado (0) e resfriado por 24 horas na dose única de $200 \times 10^{6}$ espermatozóides viáveis, pré-ovulação.

\begin{tabular}{ccccc}
\hline $\begin{array}{c}\text { Tempo de } \\
\text { armazenamento }\end{array}$ & $\begin{array}{c}N^{0} \text { de animais } \\
\text { inseminados }\end{array}$ & Dose inseminante & Prenhez \\
\hline \hline 0 & 10 & $200 \times 10^{6}$ & 20 & $100^{\mathrm{a}}$ \\
24 horas & 10 & $200 \times 10^{6}$ & 0 & $0^{\mathrm{b}}$ \\
\hline
\end{tabular}

Tabela 6: Resultado das inseminações com sêmen diluído em extensor BCT, não resfriado (0) e resfriado por 24 e 48 horas com doses diárias de $200 \times 10^{6}$ espermatozóides viáveis, pré e pós-ovulação.

\begin{tabular}{ccccc}
\hline $\begin{array}{c}\text { Tempo de } \\
\text { armazenamento }\end{array}$ & $\begin{array}{c}N^{0} \text { de animais } \\
\text { inseminados }\end{array}$ & Dose inseminante & Prenhez \\
\hline 0 & 19 & $200 \times 10^{6}$ & 19 & $1 \% 0^{\mathrm{a}}$ \\
\hline 24 horas & 10 & $200 \times 10^{6}$ & 1 & $10^{\mathrm{b}}$ \\
48 horas & 10 & $200 \times 10^{6}$ & 0 & $0^{\mathrm{b}}$ \\
\hline \hline
\end{tabular}

Tabela 7: Resultado das inseminações com sêmen diluído em extensor BT2, não resfriado (0) e resfriado por 24 e 48 horas com doses diárias de $500 \times 10^{6}$ espermatozóides viáveis, pré e pós-ovulação.

\begin{tabular}{ccccc}
\hline $\begin{array}{c}\text { Tempo de } \\
\text { armazenamento }\end{array}$ & $\begin{array}{c}\mathrm{N}^{0} \text { de animais } \\
\text { inseminados }\end{array}$ & Dose inseminante & \multicolumn{2}{c}{ Prenhez } \\
\hline \hline 0 & 14 & $500 \times 10^{6}$ & 14 & $100^{\mathrm{a}}$ \\
\hline 24 horas & 10 & $500 \times 10^{6}$ & 6 & $60^{\mathrm{a}}$ \\
48 horas & 10 & $500 \times 10^{6}$ & 0 & $0^{\mathrm{b}}$ \\
\hline \hline
\end{tabular}

feriores aos citados na literatura, considerando que reabastecendo a reserva espermática no istmo, com dose inseminante de $100 \times 10^{6}$ espermatozóides viáveis em dois dias consecutivos, pode-se maximizar a fertilidade usando sêmen resfriado (Squires et al., 1998).

Como os resultados não foram satisfatórios, realizaram-se novas inseminações com um terceiro grupo. Para este terceiro grupo, onde foi utilizada a mesma freqüência de inseminações do grupo 2 com dose inseminante de $500 \times$ $10^{6}$ espermatozóides com motilidade progressiva, observaram-se seis éguas prenhes para o tratamento 24 horas, obtendo-se resultado significativamente superior aos tratamentos de 48 horas, não diferindo do grupo que foi inseminado com sêmen diluído com BCT sem refrigeração (Tabela 7). Talvez essa melhora nos resultados de 24 horas de armazenamento esteja relacionada com a associação de inseminações artificiais pré e pós-ovulação, suprindo alguma deficiência espermática (Silva Filho, 1998) e o aumento da concentração da dose inseminante para $500 \times 10^{6}$ espermatozóides com motilidade progressiva (Demick et al.,
1976; Blancharde Varner, 1998). Ainda pode ter contribuído com esses resultados, a curva de $0,05^{\circ} \mathrm{C} / \mathrm{min}$ (Moran et al., 1992).

Com os baixos resultados de fertilidade podemos suspeitar que os espermatozóides utilizados nas inseminações poderiam estar envelhecidos. Este envelhecimento é possível quando se estoca o sêmen (Roche et al., 1968), e a conseqüência disso é a incapacidade do espermatozóide iniciar a fertilização (Nicolai e Shaver, 1977; Bell e Shaver, 1982). Essa suspeita também está de acordo com Mann e LutwakMann (1975) quando eles citam que o envelhecimento resulta em decréscimo da capacidade de fertilizar, decréscimo da motilidade espermática e aumento da mortalidade embrionária.

Além do envelhecimento espermático, podemos citar que a curva de resfriamento utilizado no primeiro e segundo grupos pode ter influenciado, pois o esperma-tozóide eqüino é mais susceptível ao choque térmico pelo resfriamento rápido entre 19 a $8^{\circ} \mathrm{C}$ (Squires et al., 1999). Outro fator que pode ter influenciado na taxa de prenhez foi a dose inseminante de $200 \times 10^{6}$, que apesar de ser suficiente para promover a prenhez (Squires et al., 1998), éguas podem ser inseminadas com, no mínimo, $100 \times 10^{6}$ com motilidade progressiva, desde que proveniente de garanhão altamente fértil, sem reduzir a fertilidade (Demick et al. 1976).

Apesar da combinação da gema de ovo com glicose poder otimizar a sobrevida espermática durante a estocagem (Bogard e Mayer, 1950), pouco se sabe do efeito da associação de outros componentes existentes no diluente Baken, utilizado neste experimento, como a taurina, o cloreto de potássio e o fosfato ácido dissódio dodecaidratado, sobre as células espermáticas no que diz respeito à fertilização.

Um estudo que cita o aumento na motilidade com o uso da taurina utilizando sêmen de garanhão (ljaz e Ducharme, 1995), não relata qualquer tipo de relação entre este aminoácido e 0 aumento da fertilidade com sêmen resfriado. Vários estudos têm sido realizados utilizando-se a taurina. Em sua grande maioria, está relacionado ao sêmen congelado de bovinos ou qualquer outra pesquisa direcionada a esta espécie (Foote et al., 1993; Chen et al., 1993; Windsor, 1997; Takahashi e Kanagawa, 1998).

\section{Conclusões}

$O$ presente trabalho mostrou que o diluente Baken contendo cefalotina mostrou ser o melhor em relação à longevidade espermática em avaliações in vitro para resfriamento de sêmen eqüino, mas o menos eficiente no controle bacteriano em relação ao BCT. Este mesmo diluente foi eficiente até 24 horas de armazenamento mediante os resultados de pre- 
nhez para concentração de $500 \times 10^{6}$ espermatozóides com motilidade progressiva uma vez que foram necessárias inseminações diárias. Além disso, o teste hiposmótico e o teste de fluorescência avaliam aspectos diferentes da mem-

\section{Apoio FAPESP.}

\section{Referências}

BACK, D.G., PICKETT, B.W., VOSS, J.L., SEIDEL Jr., G.E. Effect of antibacterial agents on the motility of stallion spermatozoa at various storage times, temperatures and dilution ration. J. Anim. Sci., v. 41, p. 137-143, 1975.

BOGARD, R., MAYER,D.T. The effects of egg yolk on the various physical and chemical factors detrimental to spermatozoa viability. J. Anim. Sci., v. 9, p. 143-152, 1950.

BELL, C.L., SHAVER, E.L. Analysis of preimplantation golden hamster conceptuses resulting from spermatozoa aged in utero. Gamete Res., v. 6, p. 199-207, 1982.

BLANCHARD, T.L.; VARNER, D.D., LOVE, C.C., HURTGEN, J.P., CUMMINGS, M.R., KENNEY, R.M. Use of sperm extender containing antibiotic to improve the fertility of stallion with seminal vesiculitis due to Pseudomonas aeruginosa. Theriogenology, v. 28, p. 541-546, 1987.

BLANCHARD, T. L., VARNER, D.D. Breeding with cooled, transported equine semen: testing and preparing semen for travel. Vet. Med., v. 93, p: $474-479,1998$.

CHEN, Y; FOOTE, R.H.; BROCKETT, C.C. Effect of sucrose, trehalose, hypotaurine, taurine, and blood serum on survival of frozen bull sperm. Cryobiology. Orlando, Fla.: Academic Press, v. 30, n. 4, p. 423-431, 1993.

DEMICK, D.S., VOSS, J.L., PICKETT, B.W. Effect of cooling, storage, glycerolization and spermatozoal numbers on equine fertility. J. Anim. Sci, v. 43, p. 633-637, 1976.

ELLORY, J.C., HALL, A.C. Temperature effects on red cell membrane transport processes. In: BOWLER, K., FULLER, B.J. (Ed.). Temperature and animals cells. Cambridge: Company of Biologists Limited, 1987, p. 53-66.

FOOTE, R.H.; CHEN, Y.; BROCKETT, C.C.; KAPROTH, M.T. Fertility of bull spermatozoa frozen in whole milk extender with trehalose, taurine, or blood serum. J. Dairy Sci. Champain, III: American Dairy Science Association, v. 76, p. 1.908-1.913, 1993.

GOODMAN, L.A. Simultaneous confidence intervals for contrasts arnong multinominal proportions. Ann. of Math. Sta., v. 35, p. 716-725, 1989.

HARRISON, R.A.P, VICKERS, S.E. Use of fluorescent probes to asses membrane integrity in mammalian spermatozoa. J. Reprod. Fertil., v. 88, p. 343-352, 1990.

HOYUMPA, A.H., MCINTOSH, A.L., VARNER, D.D., SCANLAN, C.M. Normal bacterial flora of equine semen: Antibacterial effects of amikacin, penicillin, and an amikacin-penicillin combination in a seminal extender. In: INTERNATIONAL CONGRESSOF ANIMAL REPRODUCTION, 12. 1992, Rio de Janeiro. Proceedings... Rio de Janeiro, 1992 , v. 3, p. $1.427-$ 1.429, 1992.

HUGHES, J.P., ASBURY, D.C., LOY, R.G., BURD,H.E. The occurence of $P$ seudomonas aeruginosa in the genital tract of stallion and its effects on fertility. Cornell Vet., v. 57, p. 53-59, 1967.

IJAZ, A., DUCHARME, R. Effect of various extenders and taurine on survival of stallion sperm cooled to $5^{\circ} \mathrm{C}$. Theriogenology, v. $43, \mathrm{p}$. 1.039-1.050, 1995. brana plasmática e a utilização conjunta destes testes associada aos parâmetros convencionais de avaliação seminal é indicada para se obter maiores informações sobre a célula espermática.
JASKO, D.J., BEDFORD, N.L., COOK, E.L., MUNFORD, E.L., SQUIRES, E.L. PICKETT, B.W. Effect of antibiotics on motion characteristics of cooled stallion spermatozoa. Theriogenology, v. 40, p. 885-893, 1993.

KENNEY, R.M., BERMAN, R.V., COOPER, W.L., MORSE,G.V. Minimal contamination techniques for breeding mares: technique and preliminary findings. In: ANNUALCONVENTIONAMERICANASSOCIATIONEQUINE PRACTITIONERS, 21. 1975, Boston. Proceedings..., Boston, 1975. p. 327-336.

KENNEY, R.M., HURTGEN, J., PIERSON, L. Manual for breeding soundness examination of stallion. J. Soc. Theriogenol., v. 9, p. 3, 1983.

KLUG, E. Neue chancen der intrumentellen semen-übertragung bein pferd. Tieärztl. Umschau, v. 44, p. 489-491, 1989.

KLUG, E., SCIENE, H. Infectious agents in equine sêmen. Acta Vet. Scand., suppl. 88, p. 73-81, 1992.

LAGARES, M.A., PETZOLDT, R., SIEME, H., KLUG, E.Preservação do sêmen fresco eqüino: Avaliação da integridade de membrana espermática sob condições hiposmóticas. Arq. Fac. Vet. UFRGS, v. 26, p. 29-42, 1998.

LAGARES, M.A., MEIRELLES,L.S., WALD,V.B., GREGORY, R.M., MATTOS, R.C. Manutenção da motilidade e funcionalidade da membrana plasmática do espermatozóide equino no sêmen resfriado com diferentes diluentes. Rev. Bras. Reprod. Anim., v. 23, p. 108-111,1999.

LAGARES, M.A.; MEIRELLES, L.S.; WALD, V.B.; GREGORY, R.M.; MATTOS, R.C. Efeito de diferentes diluidores sobre a membrana plasmática do espermatozóide eqüino do espermatozóide eqüino e fertilidade do sêmen resfriado. Rev. Bras. Reprod. Anim., v. 7, p. 153$156,2000$.

LOMEO, A.M., GIAMBERSIO, A.M. "Water-test": a simple method to assess sperm-membrane integrity. Int. J. Androl., v. 14, p. 278-282, 1991.

MANN, T., LUTWAK-MANN, C. Biochemical aspects of aging in spermatozoa in relation to motility and fertilizing ability. In BLANDAU, R.J. (Ed.). Aging Gametes: Their Biology and Pathology. New York: S. Karger, 1975, p. 122-150.

MORAN, D.M., JASKO, D.J., SQUIRES, E.L., AMANN, R.P. Determination of temperature and cooling rate which induced cold shock in stallion spermatozoa. Theriogenology, v. 38, p. 999-1.012, 1992.

NEILD, D., CHAVES, G.,FLORES, M., MORA, N., BECONI, M. Hypoosmotic test in equine spermatozoa. Theriogenology, v. 51, p. 721-727, 1999. NICOLAI, P., SHAVER, E.L. The cromossome complement of rabbit blastocysts resulting from spermatozoa stored at $5^{\circ} \mathrm{C}$. Biol. Reprod., v. 17, p. $640-644,1977$.

ROCHE, J.F., DZIUK, P.J., LODGE, J.R. Competition between fresh and aged spermatozoa in fertilizing rabbit eggs. J. Reprod. Fertil., v. 16, p. 155-157, 1968.

SILVA FILHO, J.M. Influência do intervalo entre a inseminação artificial com sêmen diluído, resfriado e transportado e a ovulação sobre a fertilidade de éguas. Arq. Bras. Med. Vet. Zootec., v. 50, p. 563-568, 1998. 
SQUIRES, E.L., MCGLOTHLIN, D.E., BOWEN, R.A., PICKETT, B.W. Use of antibiotics in stallion for the control of Klebsiella pneumonia and Pseudomonas aeruginosa. J Equine Vet Sci, v. 1,43 p., 1981.

SQUIRES, E.L., BRUBAKER, P.M., Mc CUE, P.M., PICKETT, B.W. Effect of sperm number and frequency of insemination on fertility of mares inseminated with cooled semen. Theriogenology, v. 49, p.743-9, 1998.

SQUIRES, E.L., PICKETT, J.K., GRAHAM, D.K., VANDERWALL, D.K., McCUE, P.M., BRUEMMER, J.E. Cooled and frozen stallion semen. In: Animal Reproduction and Biotechnology laboratory. Colorado: College of Veterinary Medicine and Biomedical Sciences - Colorado State University, 1999.

SWENSON, M.J., REECE, W.O. Sangue, circulação e sistema cardiovascular. Dukes/fisiologia dos animais domésticos. 11. ed. Rio de Janeiro: Guanabara Koogan, 1996, p. 1-7.

TAKAHASHI, Y.; KANAGAWA, H. Effects of glutamine, glycine and taurine on the development of in vitro fertilized bovine zygotes in a chemically defined medium. J. Vet. Med. Sci., v. 60, p 433-437, 1998.

TAVARES, W. Manual de antibióticos e quimioterápicos antiinfecciosos. 2. ed. São Paulo: Atheneu,1998. p. 307-412.

TISCHNER, M., KOSINIAK, K. Techniques for collection and storage of stallion semen with minimal secondary contamination. Acta Vet. Scand., suppl. 88, p. 83-90, 1992.

VAILLANCOURT, D., GUAY, P., HIGGINS, R. The effectiveness of gentamicin or polymixin $b$ for the control of bacterial growth in equine smen stored at $20^{\circ} \mathrm{C}$ or $5^{\circ} \mathrm{C}$ for up to forty-eight hours. Can J Vet Res, v. 57, p. $277-280,1993$.

VARNER, D.D. Composition of seminal extenders and its effect on motility of equine spematozoa. In: ANNUAL MEETING OF THESOCIETY FOR THERIOGENOLOGY, 1991, San Diego. Proceedings... San Diego, 1991. p. 146-150.

VARNER, D.D., McINTOSH, A.L., FORREST, D.W., BLANCHARD, T.L., JOHNSON, L. Potassium penicillin g, amikacin sulfate, or a combination in seminal extender for stallion: effects on spermatozoal motility. Proc Int Cong Anim Reprod Artif Insem, v. 12, p. 1.496-1.498, 1992.

VARNER, D.D., SCANLAN, C.M., THOMPSON, J.A., BRUMBAUH, G.W., BLANCHARD, T.L., CARLTON, C.M., JOHNSON, L. Bacteriology of preserved stallion semen and antibiotics in semen extenders. Theriogenology, v. 50, p. 559-573, 1998.

WATSON, P.F., MORRIS, G.J. Cold shock injury in animal cells. In: BOWLER, K., FULLER, B.J. (Ed.). Temperature and animals cells. Cambridge: Company of Biologists Limited, 1987, p. 311-340.

ZAR, J.R. Bioestatistical analysis. 2. ed. Englewood Cliffs: Prentice Hall, 1984, $718 \mathrm{p}$.

ZÚCCARI, C.E.S.N., PAPA, F.O. Utilização do método de fluorescência para a avaliação da integridade de membrana plasmática de eqüino. In: CONGRESSO BRASILEIRO DEREPRODUÇÃO ANIMAL, 11. 1995, Belo Horizonte. Anais... Belo Horizonte, 1995, p. 293.

ZAVOS, P.M. Hypoosmotic swelling test/funcional integrity of sperm membranes. J. Assist Reprod Technol, v. 2, p. 215-216, 1990. 